\title{
Finite Element Analysis of Flat Joints in Metallic Honeycomb Sandwich Beams
}

\author{
Nishi P Devadas ${ }^{1}$, G Sunilkumar ${ }^{2}$, Sajeeb $\mathrm{R}^{3}$ \\ ${ }^{I}\left(P\right.$ G Student, ${ }^{3}$ Professor Department of Civil Engineering, $T$ K M College of Engineering, Kollam - 5, Kerala, \\ India) \\ ${ }_{2}^{2}$ (Deputy Head, TTIC, Vikram Srabhai Space Centre, Veli, Thiruvananthapuram, Kerala, India)
}

\begin{abstract}
A typical laminated structure of great use in aeronautical/aerospace, marine and civil engineering constructions is the sandwich-type construction. In the design of sandwich structures, components must be joined in such a manner that the overall structure retains its structural integrity while performing its intended function, subjected to loads and environment. The present work focuses on the finite element analysis of flat joints in adhesively bonded metallic honeycomb sandwich beam using ANSYS 13. The flat joint considered in the study is butt joint with doubler. The load-deflection characteristics, stress distribution patters, effects of variation of core thickness, skin thickness, and adhesive film thickness on the displacement and stress distributions are studied. Results are critically reviewed and presented.
\end{abstract}

Keywords - Sandwich structures, honeycomb sandwich beam, joints in sandwich structures

\section{INTRODUCTION}

Structural sandwich panels can be considered as a special type of laminate composite where two thin, stiff, strong and relatively dense face sheets are separated by and bonded to a thick, lightweight core material. It provides various key benefits over conventional materials such as high stiffness to weight ratio as well as high bending strength to weight ratio, high compressive stress without buckling high compressive stress without buckling and excellent mechanical and sound absorption capacity [1]. The capability of the concept has been proven and is now widely accepted. As a result of this history of success a growing interest has developed in the use of honeycomb sandwich for a broad range of commercial application. Bonded honeycomb (HC) sandwich construction has been a basic structural concept in the aerospace industry for last few decades. It is also used in bridge decks, sailboats, racing boats, snow skis, water skis, kayaks, canoes and auto racing cars [2]. Analysis of sandwich structures are more involved than conventional monocoque construction as they are layered and bonded construction. The presence of shear deformable core leads to further complexity.

Literature devoted to finite element analysis (FEA) of sandwich structures is extensive. Analytical studies are available both in flat and curved sandwich elements. Many finite element (FE) models have been proposed for the analysis of sandwich plates [3], [4] and recent trends in modeling [5]. Many researchers studied the failure patterns in sandwich structures. Recent trend in research is honeycomb sandwich structures. Studies were conducted on honeycomb sandwich structures including the structural and mechanical properties of honeycomb sandwich structures [6], the theoretical and quantitative design and analysis of a honeycomb panel sandwich structure [7]. The studies related to joints in adhesively bonded honeycomb core sandwich structures are still in its infant stage. Only few studies such as experimental study of the pull-out and shear failure loads of composite sandwich insert joints [8], developing a satellite structure with the sandwich T-joint[9]. No studies have been conducted to analyze adhesively bonded sandwich joints in metallic honeycomb sandwich structure. Adhesive joining of thin section of sandwich panels is widely used in aerospace and other structures. Since no research is done on the joints in sandwich structures present work is intended to focus on the joints in adhesively bonded metallic honey comb sandwich structures. As flat joints are used widely than corner joints extensive studies are done on flat joints in honeycomb sandwich beam.

Various methods are adopted to join two flat sandwich panels. Different flat joining methods are flush faced all bonded butt joint, bonded face supported butt joint with doubler or butt joint with a doubler, bonded butt joint using ' $\mathrm{H}$ ' section extrusion, flush faced bonded joint supported by a special internal extrusion and panel section insertion method.Flat joint selected for study is a butt joint with doubler. The deflection and stress distribution, the effect of variation of skin thickness, core thickness and adhesive film thickness in a butt jointed metallic honeycomb sandwich beam is studied. Finite element package ANSYS 13 is used for this purpose. Since no analytical expressions or experimental data are available on the behavior of sandwich joints, to validate the finite element modeling exercise intended to be performed, analysis of sandwich beam using ANSYS 13 is done first. It may be noted here that sandwich beams are well studied and theoretical predictions are possible. Once the FE analysis using ANSYS13 is validated, it is then extended to study on joints in metallic honeycomb sandwich beam. 


\section{VALIDATION OF FINITE ELEMNT ANALYSIS USING ANSYS 13}

Finite element analysis of a centrally loaded simply supported aluminium honeycomb sandwich beam is done using ANSYS 13. Sandwich beam of face skin thickness $1 \mathrm{~mm}$, and adhesive film thickness of 100 micron with core thickness of $30 \mathrm{~mm}, 35 \mathrm{~mm}, 40 \mathrm{~mm}, 45 \mathrm{~mm}, 50 \mathrm{~mm}$ is used for study. 2D modeling of the metallic honeycomb sandwich beam is done using layered shell element SHELL 181. It is a four-node element with six degrees of freedom at each node: translations in the $\mathrm{x}, \mathrm{y}$, and $\mathrm{z}$ directions, and rotations about the $\mathrm{x}, \mathrm{y}$, and z-axes. The accuracy in modeling composite shell is governed by the first-order shear-deformation theory. Mesh size of $5 \mathrm{~mm}$ obtained from convergence study is used for all the analysis. Face skin is modeled as isotropic layer with modulus of elasticity $70 \mathrm{GPa}$, poisons ratio 0.33 and density $2700 \mathrm{~kg} / \mathrm{m}^{3}$. Core is modeled as orthotropic layer with modulus of elasticity $1000 \mathrm{MPa}$, longitudinal shear modulus of $220 \mathrm{MPa}$ and transverse shear modulus of $440 \mathrm{MPa}$ with density $56 \mathrm{~kg} / \mathrm{m}^{3}$ whereas adhesive layer is modeled as isotropic layer with Young's modulus of $5 \mathrm{GPa}$ and poisons ratio 0.4. Deflection at mid-span is noted down from each of these analyses. Deflection at mid-span is also calculated from theoretical equations [10]. The results obtained are graphically plotted in Fig. 1

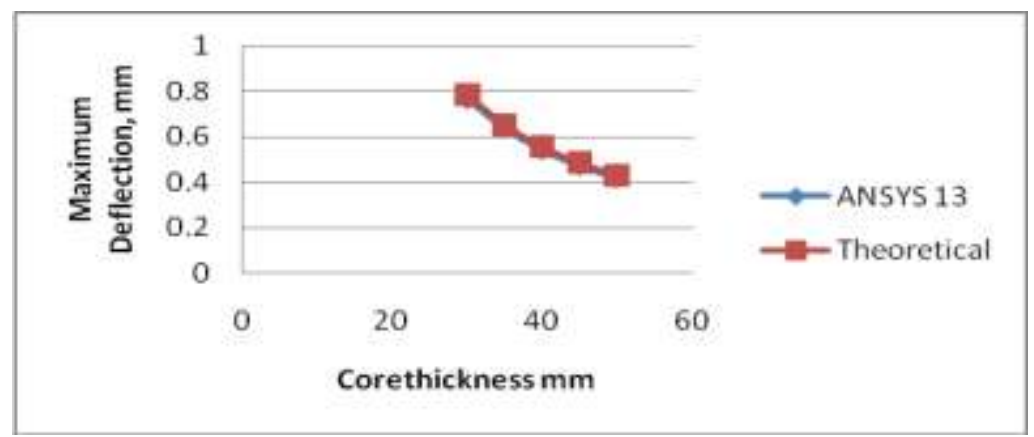

Fig. 1 Graphical comparison of results from ANSYS 13 and theoretical method

From Fig. 1 it is evident that results from ANSYS 13 are in good agreement with the theoretical results. Hence FE modeling of sandwich sections using ANSYS 13 is validated and extended to study on joints in metallic honeycomb sandwich beams.

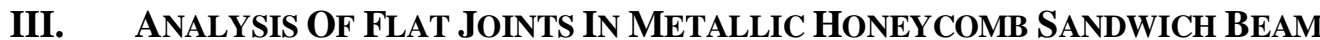

Flat joint considered for the study is a butt joint with a doubler. Doubler refers to the cover plate used to connect two panels. Doubler is used to ensure the skin/face continuity thereby maintain the structural integrity. These are connected to the parent sandwich panel by adhesive bonding. Usually doubler will be of same material and thickness of the facing skin of sandwich panel. Length of doubler is calculated from the load carrying capacity of the sandwich panel considering the shear strength of the adhesive connecting doubler and facing skin. Fig. 2 shows a butt jointed $\mathrm{HC}$ sandwich panel with a doubler.
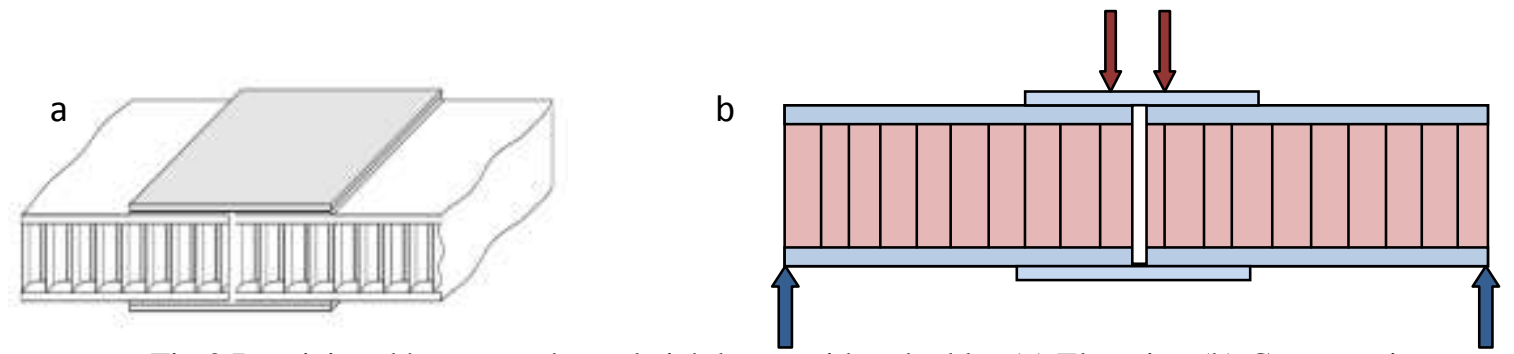

Fig.2 Butt jointed honeycomb sandwich beam with a doubler (a) Elevation (b) Cross section

Deflection and stress distribution in a butt jointed HC sandwich beam is studied. Two sandwich beams has to be joined by a doubler. For all the cases studied simply supported boundary condition was used. Table 1 gives the details of problem considered.

Table 1 Description of Problem

\begin{tabular}{|l|c|c|c|c|c|}
\hline \multirow{2}{*}{ Sandwich beam } & \multicolumn{5}{|c|}{ Components of sandwich beam } \\
\cline { 2 - 6 } & & Face & Core & Adhesive & Doubler \\
\hline $\begin{array}{l}200 \mathrm{~mm} \times 50 \mathrm{~mm} \\
\begin{array}{l}\text { Load }: 2000 \mathrm{~N} \\
\text { Simply supported }\end{array}\end{array}$ & Material & $\begin{array}{c}\text { Aluminium } \\
\text { alloy }\end{array}$ & $\begin{array}{c}\text { Aluminium } \\
\text { honeycomb } \\
\text { core }\end{array}$ & Epoxy resin & $\begin{array}{c}\text { Aluminium } \\
\text { alloy }\end{array}$ \\
\cline { 2 - 6 } & Thickness & $1 \mathrm{~mm}$ & $30 \mathrm{~mm}$ & 100 micron & $1 \mathrm{~mm}$ \\
\hline
\end{tabular}


2D modelling of the joint is done using layered shell element in ANSYS 13. Geometry is developed using key points, lines and areas. In total there are 5 areas. Material properties adopted are same as in the analysis of sandwich beam. A degraded material is also created to account for the void space due to discontinuous core. Element used is SHELL 181. Three shell elements are used as there are three different shell sections in butt joint with doubler. While meshing proper care should be taken to ensure that shell section corresponding to each layer is properly assigned. This is done with the help of mesh attribute tool. Mesh size adopted for the study is $5 \mathrm{~mm}$, obtained from convergence study. Total number of nodes and elements in the model are 902 and 812 respectively. Boundary conditions and loads are applied and model is analyzed. Deflection and stress pattern in the joint is studied.

Various parameters affecting the behavior of a sandwich panel are skin thickness (face and doubler) and core thickness. A parametric study is also done on butt jointed sandwich panel with a doubler. The aim of the parametric study was to understand the effect of the variation of face thickness and core depth in a butt jointed sandwich panel. Two sandwich panel of size $200 \times 50 \mathrm{~mm}$ has to be joined by a doubler. Length of doubler adopted for study was $100 \mathrm{~mm}$ in all the cases. Thickness of doubler was same as that of the face skin thickness. Three skin thicknesses was used for the study, $1 \mathrm{~mm}, 1.5 \mathrm{~mm} .2 \mathrm{~mm}$ and core depth was varied from $30 \mathrm{~mm}$ to $70 \mathrm{~mm}$ in a step size of $10 \mathrm{~mm}$. Load was increased from $2000 \mathrm{~N}$ to $10000 \mathrm{~N}$ in a step size of $2000 \mathrm{~N}$. Both deflection and stress pattern was noted down in each analysis. To study the effect of adhesive film thickness adhesive films of thickness 10micron, 50 micron and 100 micron was used. Results are graphically plotted to arrive at conclusions.

\section{RESULTS AND DISCUSSIONS}

Deflection and stress pattern in a simply supported butt jointed honeycomb sandwich beam subjected to central load is obtained from ANSYS 13. Fig. 3 shows the deflection and stress pattern in butt jointed HC sandwich beam with a doubler subjected to a load of $2000 \mathrm{~N}$. Thickness of face sheets and doubler is $1 \mathrm{~mm}$ and that of core is $30 \mathrm{~mm}$.
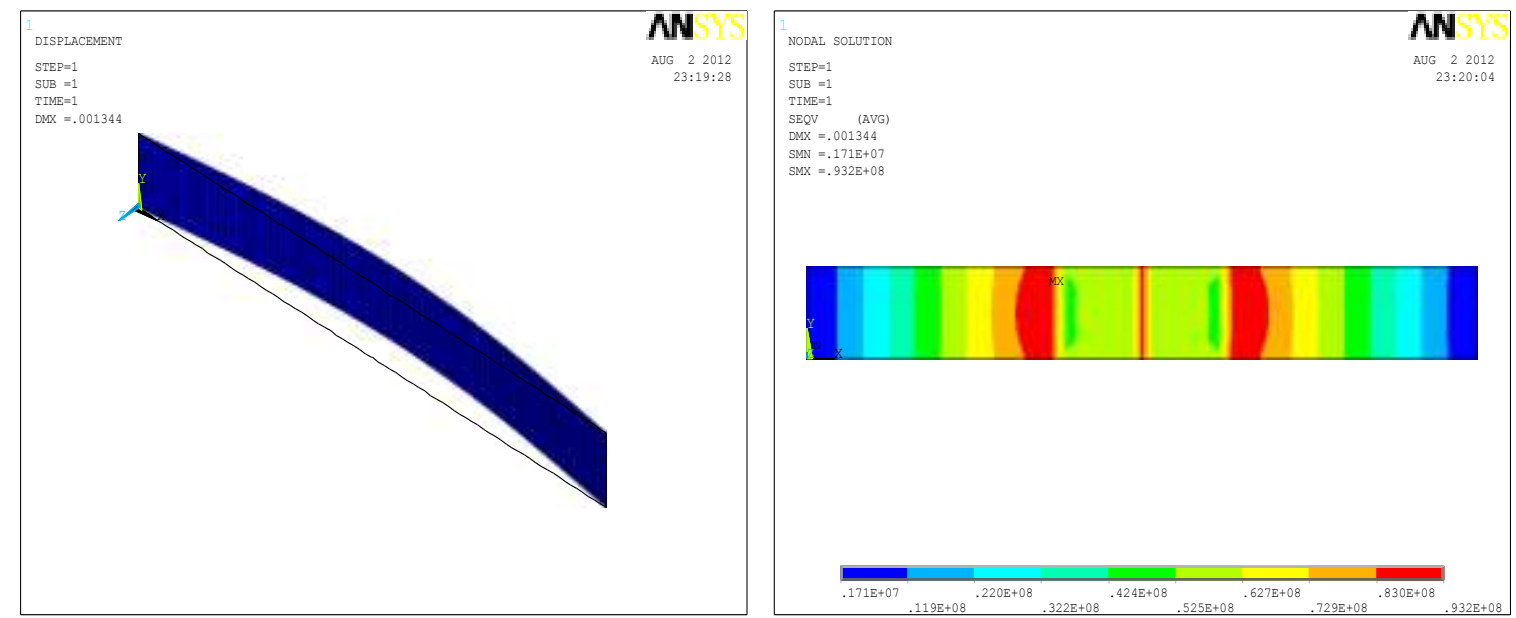

Fig. 3 Deflection and Stress in a Simply Supported Butt Jointed Sandwich Beam at a Load of 2000N

Butt jointed honeycomb sandwich beam with a doubler shows a symmetric pattern of deflection. Maximum deflection in the jointed beam is $1.344 \mathrm{~mm}$. Due to the presence of core in the sandwich structure, effect of shear deformation should also be considered. So deflection in a sandwich structure will be the sum total of bending deflection and shear deflection. Due to its exceptionally high bending stiffness, deflection will be far less than that in isotropic construction. From the stress contour for the flat joint considered for the study, it is clear that a symmetric stress pattern is shown by the joint. Maximum stress occurs at points where there is a change in cross section. Maximum stress occurs in doubler than in face at jointed areas.

Parametric study is conducted to study the effect of variation of skin thickness (both face and doubler), core thickness and adhesive film thickness. Fig. 4 shows the effect of variation of core thickness on maximum deflection in a simply supported butt jointed sandwich beam at a load of $200 \mathrm{~N}$ for skin thickness of $1 \mathrm{~mm}$, $1.5 \mathrm{~mm}$ and $2 \mathrm{~mm}$. 


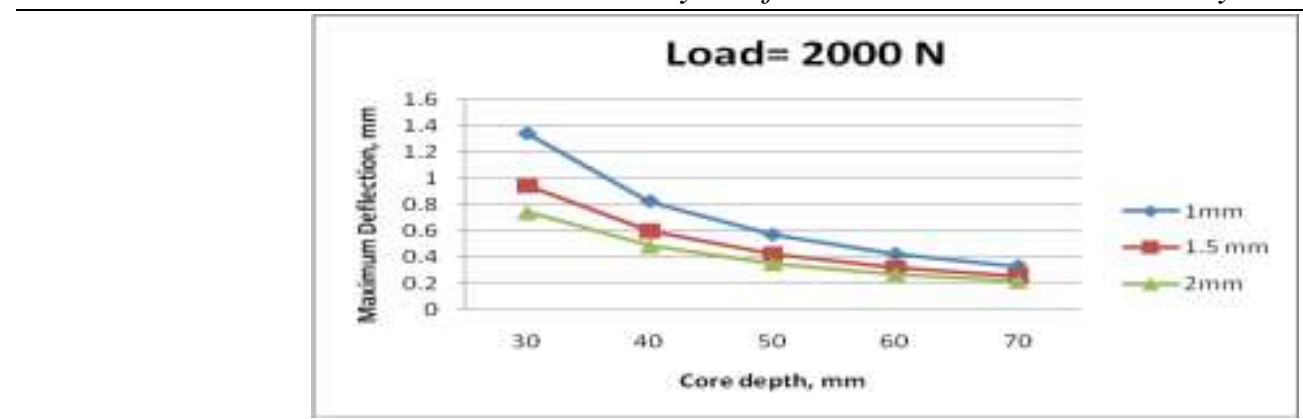

Fig. 4 Effect of variation of core thickness on maximum deflection at $2000 \mathrm{~N}$ for different skin thicknesses

From Fig. 4, it is observed that for all skin thickness as the core thickness increase the deflection decreases parabolically. The maximum deflection in joint with skin thickness of $1 \mathrm{~mm}$ and subjected to a load of $2000 \mathrm{~N}$ at core thicknesses of $30 \mathrm{~mm}, 400 \mathrm{~mm}, 50 \mathrm{~mm}, 60 \mathrm{~mm}$ and $70 \mathrm{~mm}$ are respectively $1.344 \mathrm{~mm}, 0.827 \mathrm{~mm}$, $0.571 \mathrm{~mm}, 0.424 \mathrm{~mm}, 0.332 \mathrm{~mm}$. Whereas for a skin thickness of $1.5 \mathrm{~mm}$ and $2 \mathrm{~mm}$ the maximum deflection of the joint for same load are $0.946 \mathrm{~mm}, 0.602 \mathrm{~mm}, 0.426 \mathrm{~mm}, 0.323 \mathrm{~mm}, 0.257 \mathrm{~mm}$ and $0.744 \mathrm{~mm}, 0.486 \mathrm{~mm}$, $0.219 \mathrm{~mm}$ respectively. This is due to the increase in bending stiffness of the sandwich beam due to increase in core thickness. With increase in core thickness the value of centre to centre distance between faces, $h$, increase whereas all other parameters related to bending stiffness remains the same. Variation of $h$ is in square power, hence the variation is parabolic. It is also important to note that at higher core thickness $(70 \mathrm{~mm})$ almost same deflection occurs in the joint for all skin thicknesses. So in can be inferred that if we are using higher core thickness a skin thickness of $1 \mathrm{~mm}$ is enough. There is no need for further increase of skin thickness beyond $1 \mathrm{~mm}$. Similar trend is obtained for all other load values.

At all load values, percentage decrease in maximum deflection decrease with an increase in skin thickness and core thickness. The percentage decrease in maximum deflection for a core thickness increase of $30 \mathrm{~mm}$ to $40 \mathrm{~mm}$ for a skin thickness of $1 \mathrm{~mm}, 1.5 \mathrm{~mm}, 2 \mathrm{~mm}$ are $38 \%, 36 \%$ and $29 \%$ respectively. The percentage decreases in deflection for a core thickness increase from $40 \mathrm{~mm}$ to $50 \mathrm{~mm}$ for $1 \mathrm{~mm}, 1.5 \mathrm{~mm}$ and $2 \mathrm{~mm}$ are respectively $31 \%, 28 \%$ and $27 \%$. For a core thickness increase of $50 \mathrm{~mm}$ to $60 \mathrm{~mm}$ and $60 \mathrm{~mm}$ to $70 \mathrm{~mm}$, the percentage decrease in deflection for $1 \mathrm{~mm}, 1.5 \mathrm{~mm}$ and $2 \mathrm{~mm}$ skin thickness are respectively $26 \%$, $24 \%, 23 \%$ and $22 \%, 20.5 \%, 19 \%$. This difference is due to difference in the increase in bending stiffness in each case. That is percentage increase in bending stiffness for a core thickness increase of $30 \mathrm{~mm}$ to $40 \mathrm{~mm}$ in higher than that due to increase in core thickness from $40 \mathrm{~mm}$ to $50 \mathrm{~mm}$. Since linear analysis is conducted same trend will be shown by all load values. Hence for a same core thickness increase, the percentage decrease in deflection remains same at all core thickness and load values.

Effect of variation of core thickness on maximum stress in a butt jointed honeycomb sandwich beam was also studied. For all load values similar trend was obtained. Fig. 5 shows the effect of variation of core thickness on maximum stress in a simply supported butt jointed sandwich beam at a load of $2000 \mathrm{~N}$ for different skin thickness.

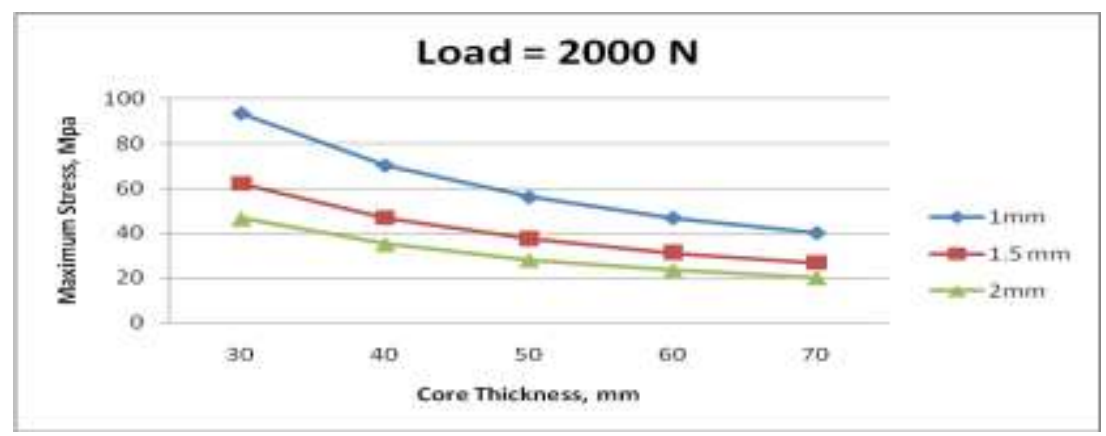

Fig. 5 Effect of variation of core thickness on maximum stress for $2000 \mathrm{~N}$ for different skin thicknesses

From Fig. 5 it is clear that for a particular load and skin thicknesses a parabolic decreasing trend is shown by maximum stress with increasing core thickness. As the core depth increases deflection and stresses at the joint decrease. The maximum stress in joint with skin thickness of $1 \mathrm{~mm}$ and subjected to a load of $2000 \mathrm{~N}$ at core thicknesses of $30 \mathrm{~mm}, 400 \mathrm{~mm}, 50 \mathrm{~mm}, 60 \mathrm{~mm}$ and $70 \mathrm{~mm}$ are respectively $93.20 \mathrm{MPa}, 70.11 \mathrm{MPa}, 56.10$ $\mathrm{MPa}, 46.80 \mathrm{MPa}$ and $40.20 \mathrm{MPa}$. For a skin thickness of $1.5 \mathrm{~mm}$ and $2 \mathrm{~mm}$ the maximum stress for same load are respectively $311 \mathrm{MPa}, 234 \mathrm{MPa}, 187 \mathrm{MPa}, 156 \mathrm{MPa}, 134 \mathrm{MPa}$ and $233 \mathrm{MPa}, 175 \mathrm{MPa}, 141 \mathrm{MPa}, 117 \mathrm{MPa}$, $100 \mathrm{MPa}$ respectively. Various parameters influencing the stress in a sandwich beam are bending moment, width, centre to centre distance between face and face thickness. With an increase in core height the value of centre to centre distance will increase. Since the centre to centre distance of face skins are inversely related to 
the stress, it decreases with increase in core thickness. For load below $8000 \mathrm{~N}$ the stress in sandwich joint with a skin thickness of $1 \mathrm{~mm}$ are acceptable. Hence for loading till $8000 \mathrm{~N}$ a face skin thickness with a doubler thickness of $1 \mathrm{~mm}$ is adequate. For higher load $(10,000 \mathrm{~N})$ as stress in joint for a skin thickness of $1.5 \mathrm{~mm}$ are acceptable from stress point of view there is no need of increasing skin thickness beyond $1.5 \mathrm{~mm}$. Percentage decrease in maximum stress due to increase in core thickness remains same for all load values and skin thicknesses. For a skin thickness increase of $30 \mathrm{~mm}$ to $40 \mathrm{~mm}$ the percentage decrease in stress for all skin thickness considered is $24 \%$. Whereas a core thickness increase of $40 \mathrm{~mm}$ to $50 \mathrm{~mm}, 50 \mathrm{~mm}$ to $60 \mathrm{~mm}$ and 60 $\mathrm{mm}$ to $70 \mathrm{~mm}$ result in a percentage decrease of stress of $20 \%, 17 \%$ and $14 \%$ respectively.

The thickness of face skin and doubler is an important parameter affecting the joint strength. Fig. 6 shows the effect of variation of skin thickness (face and doubler) on deflection in a simply supported butt jointed sandwich panel at a constant core depth.

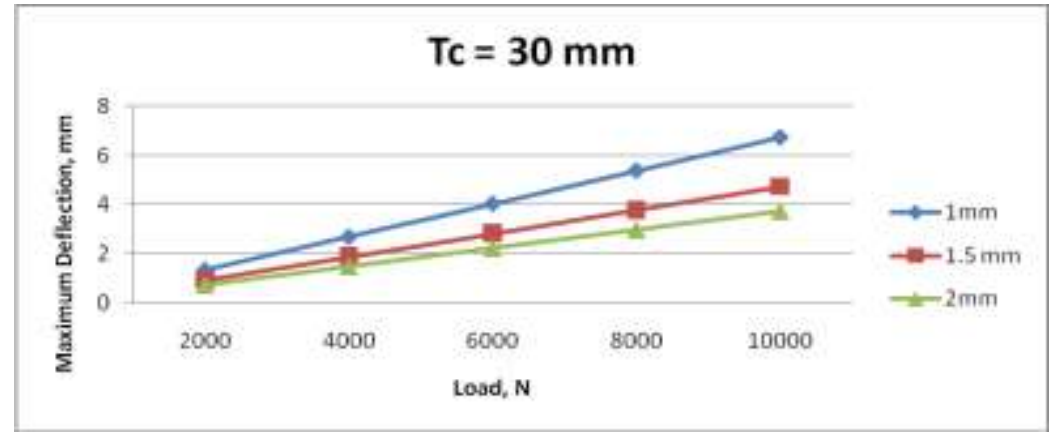

Fig. 6 Effect of variation of skin thickness with load on maximum deflection at core thickness $\mathrm{Tc}=30 \mathrm{~mm}$

Fig. 6 shows that maximum deflection varies linearly with respect to increase in skin thickness. For a core thickness of $30 \mathrm{~mm}$ and load of $2000 \mathrm{~N}$ the maximum deflection for a skin thickness of $1 \mathrm{~mm}, 1.5 \mathrm{~mm}$ and $2 \mathrm{~mm}$ are $93.2 \mathrm{MPa}, 62.10 \mathrm{MPa}$ and $46.50 \mathrm{Mpa}$. The reduction in deflection is due to the increase of bending stiffness. Here the increase in bending stiffness is due to an increase of centre to centre distance of face skin as well as increase of skin thickness itself. Same behavior is shown by the joint for all the core thickness. At a constant load, the percentage decrease in deflection by increasing skin thickness from $1 \mathrm{~mm}$ to $1.5 \mathrm{~mm}, 1.5 \mathrm{~mm}$ to $2 \mathrm{~mm}$ and $1.5 \mathrm{~mm}$ to $2 \mathrm{~mm}$ decrease with an increase in core thickness. The percentage decrease in deflection for a core thickness of $30 \mathrm{~mm}$ for a skin thickness increase of $1 \mathrm{~mm}$ to $1.5 \mathrm{~mm}, 1 \mathrm{~mm}$ to $1.5 \mathrm{~mm}$ and $1.5 \mathrm{~mm}$ to $2 \mathrm{~mm}$ is $30 \%, 44 \%$ and $21 \%$. For core thickness of $40 \mathrm{~mm}$ the percentage decrease of deflection drops down to $27 \%$, $41 \%$ and $21 \%$. This reduction in deflection is in accordance with the increase of bending stiffness of the joint. At a particular core thickness maximum deflection show the same percentage decrease at different load values, due to increase in core thickness. It may be noted that the percentage increase in bending stiffness by increasing skin thickness from 1 to1.5mm is higher than by increasing it from $1.5 \mathrm{~mm}$ to $2 \mathrm{~mm}$.

Fig. 7 shows the effect of skin thickness variation on maximum stress in a simply supported butt jointed sandwich beam with a doubler at a constant core depth.

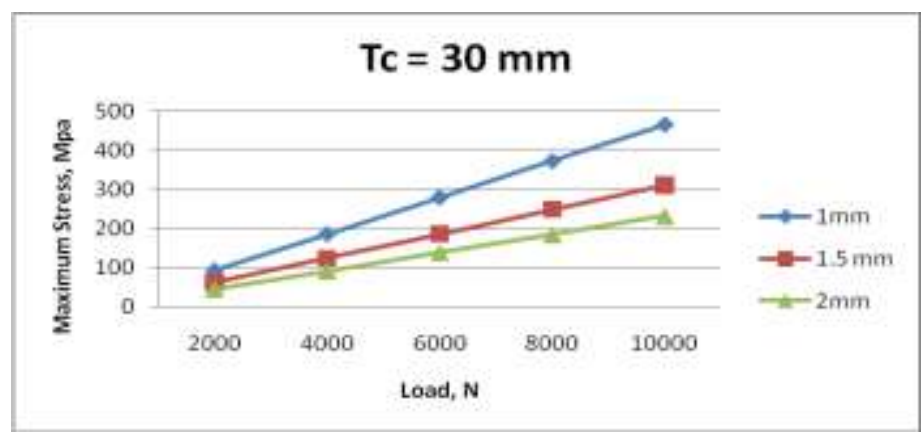

Fig. 7 Effect of variation of skin thickness with load on maximum stress at core thickness of $30 \mathrm{~mm}$

Fig. 7 evidently shows that, at a constant core thickness maximum stress show a linearly increasing trend with load, similar to deflection. Also at a constant core depth, both Stress and deflection in butt jointed sandwich panel with doubler follow a linearly decreasing trend with increase in skin thickness. This may be attributed to combined effect of increase in cross section and decrease in deflection. It can be inferred from the graphical plots that there is no need of increasing skin thickness beyond $1.5 \mathrm{~mm}$, as the stress values for $1.5 \mathrm{~mm}$ skin sandwich joint are acceptable for all the load cases considered. At a constant load, percentage decrease in 
maximum deflection was lesser comparative to that in maximum stress in all the cases considered. It is also interesting to note that at a constant load, the percentage decrease in maximum stress is observed to be same at all load values as well as core thicknesses. The coupled effect of reduction in deflection and increase in cross sectional area is responsible for the decrease of stress, which remains same for all core thickness. The numerical value of percentage decrease in maximum stress at various loads at a constant core thickness for an increase in skin thickness from $1 \mathrm{~mm}$ to $1.5 \mathrm{~mm}, 1 \mathrm{~mm}$ to $2 \mathrm{~mm}$ and $1.5 \mathrm{~mm}$ to $2 \mathrm{~mm}$ is approximately $33 \%, 50 \%$ and 24\% respectively

Third component in a sandwich construction is adhesive layer. Adhesive bonding is used in sandwich panels to joint individual laminate. Usually epoxy resins are used for this purpose. To study the effect of adhesive film thickness adhesive films of thickness 10micron, 50 micron and 100 micron was used. For all the cases the deflection and stress was almost same. Effect of adhesive film thickness is mainly reflected in the shear stress coming on them. Shear stress in the adhesive film between the doubler and face skin was noted across the lap length. Fig 8 shows the schematic sketch of the location studied.

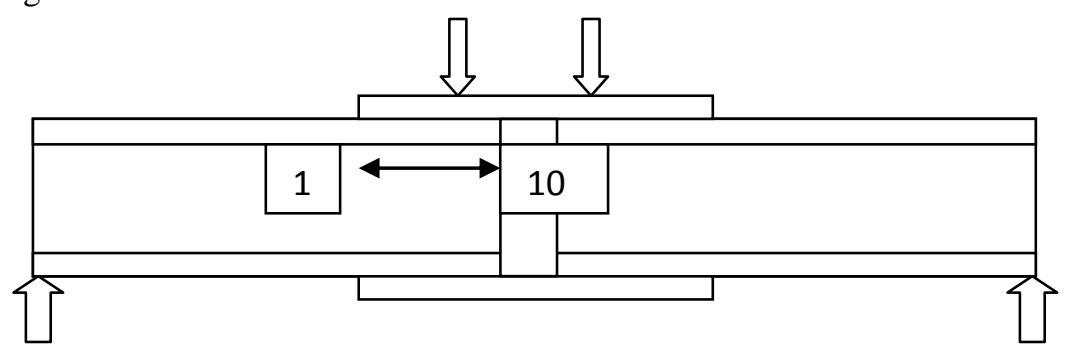

Fig. 8 Schematic Sketch of the Location of Nodes for which Stress in Adhesive Film was noted

Fig. 9 gives graphical representation of effect of variation of adhesive film thickness, on the stress in the adhesive film across the lap length in a simply supported butt jointed sandwich beam

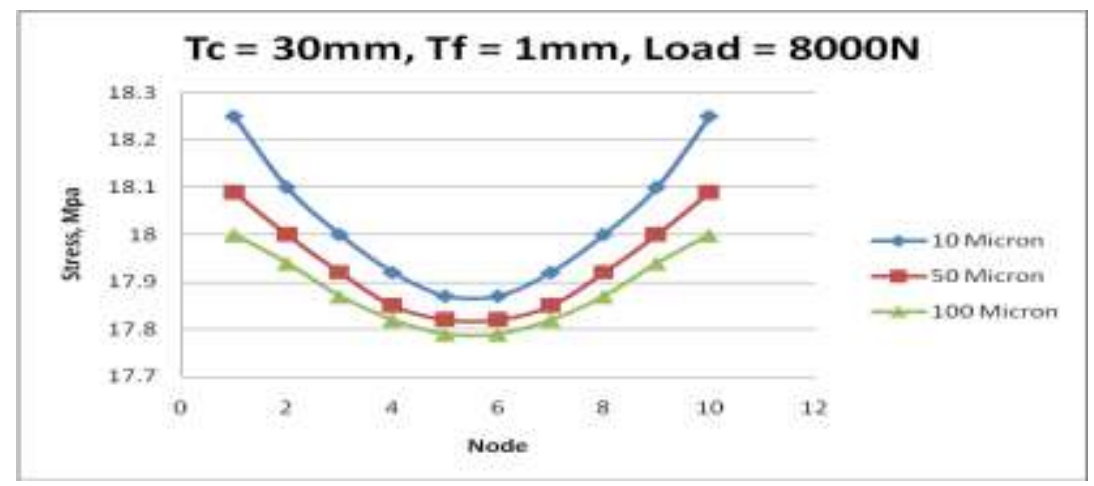

Fig. 9 Variation in Stress in Adhesive Layer with Film Thickness

It can be observed that stress in adhesive layer across the lap length shows a parabolic trend. As the adhesive layer thickness increases the curve gets flattened. Increase in adhesive film thickness doesn't reduce the stress considerably. Hence adhesive films of small thickness would be sufficient in many situations which may lead to reduction in cost.

\section{CONCLUSIONS}

Honeycomb sandwich construction is one of the most valued structural engineering innovations combine high flexural rigidity and bending strength with low weight. Among the various honeycomb sandwich structures adhesively bonded aluminium honeycomb sandwich panels are currently popular because of their ease of assembly. Joints are unavoidable in almost all applications of sandwich panels. But no research has been conducted on adhesive joints in metallic honeycomb sandwich structures. The present study focussed on the behaviour of honeycomb sandwich joints. Detailed investigations, using finite element analysis, of butt jointed honeycomb sandwich beam with a doubler are performed. The study includes load - deflection characteristics and parametric studies. arrived at.

From the study of simply supported butt jointed honeycomb sandwich beams various conclusions were 
a. In a butt jointed honeycomb sandwich beam the optimum range of doubler and face skin thickness is $1 \mathrm{~mm}$ to $1.5 \mathrm{~mm}$. Further increase in thickness of doubler and face skin does not have much effect on joint strength.

b. At a constant skin thickness and load values, both maximum deflection and maximum stress shows a parabolic decreasing trend with an increasing core thickness. This parabolic decreasing trend in deflection is due to the increase of bending stiffness due to increase in centre to centre distance of face skins.

c. The percentage decrease in maximum deflection decrease with an increase in skin thickness and core thickness at all load values, which can be attributed to the differential increase in bending stiffness in each case. Percentage decrease in stress is due to increase in centre to centre distance with increasing core thickness and remains same for all load values and skin thicknesses.

d. At a constant core thickness and skin thickness, the maximum deflection and stress in a joint increase linearly with load. There is a reduction in stress and deflection as the skin thickness increases. This may be due to the increase in cross sectional area and increase in bending stiffness of the joint.

e. At a particular core thickness maximum deflection show the same percentage decrease at different load values, due to increase in core thickness. It may be noted that the percentage increase in bending stiffness by increasing skin thickness from 1 to $1.5 \mathrm{~mm}$ is higher than by increasing it from $1.5 \mathrm{~mm}$ to $2 \mathrm{~mm}$.

f. Face skin shows a lower stress than that in doubler in the jointed area.

g. Stress in adhesive layer across the lap length shows a parabolic trend. As the adhesive layer thickness increase the curve gets flattened. The maximum stress for a 10 micron adhesive film and 100 micron film is respectively $18.25 \mathrm{MPa}$ and $18.10 \mathrm{MPa}$ this infers that a 10 micron film is adequate in many of the situations

The study can be extended to other types of adhesive flat joints and corner joints in metallic honeycomb sandwich beams.

\section{REFERENCES}

[1] H.G Allen, Analysis and design of structural sandwich panels (Pregmon Press, Oxford, 1969).

[2] Jack R Vinson, Behaviour of sandwich structures of isotropic and composite materials (Pennsylvania, Taylor and Francis Routledge, 1999)

[3] Ha K.H, Finite element analysis of sandwich plates An overview, Computers and Structures, 37, 1990, 397 - 403

[4] Hussanih. Ai-Qarra, Finite deflection of sandwich beams and plates by finite element method, Journal of Engineering Mechanics, 115, 1989, 1318-1335

[5] Liviu L and H Teery, Recent developments in the modeling and behavior of advanced sandwich constructions A survey, Composite Structures, 48, 2000, 1- 17

[6] Meifing H and H Wenbin, A study on composite honeycomb sandwich panel structure, Material and design, 29, 2008, 709-713

[7] Gaetano G. G, V Christine and S E Omar, Theoretical design and analysis of a honeycomb panel sandwich structure loaded in pure bending, Engineering failure analysis, 15, 2008, 555 - 562

[8] Keun-I S, C Ji-Young, K Jin-Hwe, C Jin-Ho, K Kwang-Soo Kim, An experimental study of joint strength of composite sandwich structures, Composites and Structures, 86, 2008, 107-113

[9] Byoung J.K and G L Dai, Development of a satellite structure with the sandwich T Joint, Composite structures, 92, 2010, 460-468.

[10] Carlson L.A and G.A Kardomates, Structural and failure mechanism of sandwich composites, (London, Springer, 2011) 